\begin{tabular}{|c|c|c|c|}
\hline \multirow{2}{*}{$\begin{array}{r}\text { Case Reports in } \\
\text { Gastroenterology }\end{array}$} & \multicolumn{2}{|c|}{ Case Rep Gastroenterol 2018;12:1-6 } & \multirow[b]{2}{*}{$\begin{array}{l}\text { Karger } \\
\text { Open access }\end{array}$} \\
\hline & $\begin{array}{l}\text { DOI: 10.1159/000485557 } \\
\text { Publisned online: January 5, } 2018\end{array}$ & $\begin{array}{l}\text { (C) } 2018 \text { The Author(s) } \\
\text { Published by S. Karger AG, Basel } \\
\text { www.karger.com/crg }\end{array}$ & \\
\hline & $\begin{array}{l}\text { This article is licensed under th } \\
\text { International License (CC BY-NC } \\
\text { Usage and distribution for comme }\end{array}$ & $\begin{array}{l}\text { nons Attribution-NonCommercial } 4.0 \\
\text { ger.com/Services/OpenAccessLicense). } \\
\text { uires written permission. }\end{array}$ & \\
\hline
\end{tabular}

\title{
ERCP-Related Duodenal Perforation Presenting as Pneumoscrotum
}

\author{
Mohammad Saud Khan $^{\mathrm{a}}$ Faisal Jamal $^{\mathrm{b}} \quad$ Zubair Khan $^{\mathrm{a}} \quad$ Abhinav Tiwari $^{\mathrm{a}}$ \\ Hermann Simo ${ }^{a}$ Himani Sharma $^{a}$ \\ ${ }^{a}$ Department of Internal Medicine, University of Toledo Medical Center, Toledo, OH, USA; \\ ${ }^{b}$ Department of Radiology, Apollo Hospitals, New Delhi, India
}

\section{Keywords}

Endoscopic retrograde cholangiopancreatography $\cdot$ Duodenal perforation $\cdot$ Pneumoscrotum

\begin{abstract}
Duodenal perforation is a rare but life-threatening complication of endoscopic retrograde cholangiopancreatography (ERCP). Duodenal perforation can cause air leak into the extraperitoneal space. In rare instances, the air in the extraperitoneal space could dissect along the fascial planes of the abdomen to reach scrotum, leading to pneumoscrotum. We present the case of a 35-year-old male patient who developed scrotal pain and swelling following ERCP. He was found to have extensive pneumoscrotum, pneumoretroperitoneum, pneumomediastinum, and subcutaneous emphysema. The patient was diagnosed with retroperitoneal duodenal perforation. He was managed conservatively with close monitoring and supportive care.

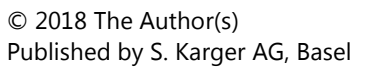

\section{Introduction}

Endoscopic retrograde cholangiopancreatography (ERCP) is a commonly used procedure for diagnosis and treatment of pancreatobiliary disorders. It is generally considered a safe procedure, and complications are uncommon. The incidence of ERCP-related complications has varied widely among studies, ranging from 5 to $10 \%$ [1]. Common complications of ERCP include pancreatitis, hemorrhage, cholangitis, and visceral perforation $[2,3]$. The oc- 


\section{Case Reports in \\ Gastroenterology}

Case Rep Gastroenterol 2018;12:1-6

DOI: $10.1159 / 000485557$

Khan et al.: ERCP-Related Duodenal Perforation Presenting as Pneumoscrotum

currence of these complications depends on patient selection, operator skill, and complexity of procedure [1]. Visceral perforation is a rare complication related to ERCP and is seen in $<1 \%$ cases [4]. Duodenum is the most common site of perforation related to ERCP. Duodenal perforation causes leakage of bowel contents along with intraluminal air in the peritoneal and extraperitoneal space. In rare instances, the air in the extraperitoneal space could dissect along the fascial planes of the abdomen to reach the scrotum, leading to pneumoscrotum [5].

\section{Case Description}

A 35-year-old male initially presented with a 1-day history of severe upper abdominal pain with nausea and vomiting. The patient had been having intermittent episodes of upper abdominal pain along with yellow discoloration of eyes and urine for the past 2 months. On physical examination, the patient was afebrile and icteric. He had tachycardia, with a heart rate between 110 and 120 beats/min, and normal blood pressure. Abdominal examination showed right upper quadrant tenderness without any rigidity or guarding. Initial laboratory workup was significant for conjugated hyperbilirubinemia with direct bilirubin of $4.3 \mathrm{mg} / \mathrm{dL}$ $(0-0.3 \mathrm{mg} / \mathrm{dL})$ and raised alkaline phosphatase of $372 \mathrm{IU} / \mathrm{L}$ (36-92 IU/L). Ultrasonography of the abdomen showed multiple small calculi in the gall bladder with distended lumen; the common bile duct (CBD) was dilated at $16 \mathrm{~mm}$ with an impacted calculus at its lower end. The patient underwent ERCP during which CBD was cannulated with a guidewire, and endoscopic sphincterotomy was performed. Biliary drainage was obtained, and stones were extracted. Few hours after the procedure, the patient developed scrotal pain and swelling. The pain radiated to his abdomen and down to his thighs. He was afebrile, and vital signs were normal. On examination, his scrotum was diffusely enlarged 3-4 times the normal size; no skin erythema or necrosis was noted (Fig. 1). Crepitus was palpated in the scrotal skin and in the adjacent perennial region. Scrotal ultrasound was done, which did not show any fluid collection; however, it showed presence of air in the scrotal sac with reflection of ultrasound waves limiting further evaluation (Fig. 2B). An abdominal radiograph showed enlarged scrotal soft tissue shadow with presence of air in the fascial planes concerning for subcutaneous emphysema (Fig. 2A). CT of the abdomen and pelvis showed extensive pneumoscrotum, pneumoretroperitoneum, pneumomediastinum along with subcutaneous emphysema involving the soft tissue of abdomen and perineum (Fig. 3 and 4). The pneumoretroperitoneum was predominant in the right paraduodenal region and right abdominal quadrant, raising the possibility of duodenal perforation; however, no definite contrast extravasation was seen. A diagnosis of retroperitoneal duodenal perforation was made. The patient was managed conservatively with close monitoring and supportive care. He was kept nil per oral with intravenous fluids and antibiotics. The patient remained stable over time and was started on clear liquid diet subsequently, which he tolerated well. He reported improvement in symptoms and was discharged home.

\section{Discussion}

Duodenal perforation is a rare but serious complication related to ERCP. ERCP-related perforations can occur during handling or manipulation of the endoscope, endoscopic 


\section{Case Reports in Gastroenterology}

Case Rep Gastroenterol 2018;12:1-6

DOI: $10.1159 / 000485557$

(C) 2018 The Author(s). Published by S. Karger AG, Basel www.karger.com/crg

Khan et al.: ERCP-Related Duodenal Perforation Presenting as Pneumoscrotum

sphincterotomy, or insertion of the guidewire [6]. The clinical outcome of duodenal perforations can be minimal to severe depending on the type and location of the perforation [7].

Stapfer et al. [8] classified iatrogenic duodenal perforations into four categories. Type 1 injury is the perforation of the medial or lateral wall of the duodenum. It mostly occurs as a result of direct injury from the distal end of the endoscope and results in considerable spillage of duodenal contents into the intra or extraperitoneal space. Type 1 injury is associated with severe outcome and typically requires early surgical intervention [8]. Delay in diagnosis is usually associated with high mortality. Type 2 injury is the perivaterian duodenal perforation that usually occurs during endoscopic sphincterotomy. It varies in severity and requires either a surgical or medical management [8, 9]. Type 3 injury is the perforation of the distal bile duct that occurs during guidewire or basket instrumentation. Usually, this kind of perforation is small, and medical management is sufficient in most of the cases [6, 8]. Type 4 injury is the air leakage to retroperitoneum due to microperforations and is managed medically $[6,8]$. This classification is well correlated with the order of severity and helps in predicting early surgical intervention versus more conservative approach.

Duodenal perforation can have a variable presentation and can range from asymptomatic state to full-blown peritonitis and sepsis [7]. Common symptoms include nausea, vomiting, fever, abdominal pain, and distension. Rarely, duodenal perforation can present with the symptoms of extraperitoneal air leak resulting in subcutaneous emphysema and very rarely in pneumoscrotum. Air, after leaking into the retroperitoneal space, most commonly travels upwards through the diaphragmatic hiatus resulting in pneumomediastinum [5]. This air can further dissect along fascial planes and subcutaneous tissues of the neck presenting as subcutaneous emphysema. However, in rare circumstances, the retroperitoneal air can travel downwards along fascial planes to reach the scrotum, resulting in pneumoscrotum $[5,10]$. Abdominal fascial planes include the superficial fascia of Camper and deep fascia of Scrapa. These fasciae are distinct in the abdomen but fuse to form Colles' fascia at the base of the penis and Darto's fascia in the testes. Air can track along these fascial planes to reach the scrotum $[5,10]$. Also, the retroperitoneal air in the perinephric space can diffuse through the inguinal canal along the spermatic fascia to reach the scrotum [5].

Pneumoscrotum is a rare clinical entity and can be due to primary or secondary etiology. Primary pneumoscrotum is derived from the local production of air within the scrotal wall or scrotal contents. Secondary pneumoscrotum is caused by air produced elsewhere in the body, which travels to scrotum [11]. On review of the literature, we found only 5 reported cases of pneumoscrotum following ERCP. Klimach et al. [12] in 1990 reported the first case of pneumoscrotum resulting from ERCP and endoscopic sphincterotomy. Since then, 4 more cases of pneumoscrotum following ERCP and/or endoscopic sphincterotomy have been reported [13-16]. The median age among the reported cases was 64 years. Of these 5 patients, 3 underwent ERCP for choledocholithiasis, 1 for obstructive jaundice secondary to malignancy, and 1 for postcholecystectomy syndrome. All the patients developed symptoms of scrotal swelling either on the same day or the day following the procedure. All 5 cases were managed conservatively without any surgical intervention. Four out of these 5 patients had favorable outcome with complete recovery, while 1 patient developed sepsis and shock and eventually died. To our knowledge, this is the 6th reported case of pneumoscrotum following ERCP. In our case, there was a significant amount of air leak leading to extensive accumulation of air in the scrotal sac, as compared to previous reported cases in which the findings were subtle. 
In conclusion, scrotal swelling due to pneumoscrotum can be the initial presentation of duodenal perforation, caused by invasive procedures like ERCP. Therefore, clinicians should be cognizant of this complication, as early recognition is critical for a successful outcome.

\section{Statement of Ethics}

The authors have no ethical conflicts to declare.

\section{Disclosure Statement}

The authors declare that there is no conflict of interest regarding the publication of this paper.

\section{References}

1 Szary NM, Al-Kawas FH: Complications of endoscopic retrograde cholangiopancreatography: how to avoid and manage them. Gastroenterol Hepatol 2013;9:496-504.

-2 ASGE Standards of Practice Committee, et al: Complications of ERCP. Gastrointest Endosc 2012;75:467473.

-3 Freeman ML, et al: Complications of endoscopic biliary sphincterotomy. N Engl J Med 1996;335:909918.

4 Enns R, et al: ERCP-related perforations: risk factors and management. Endoscopy 2002;34:293-298.

5 Watson HS, Klugo RC, Coffield KS: Pneumoscrotum: report of two cases and review of mechanisms of its development. Urology 1992;40:517-521.

6 Cho KB: The management of endoscopic retrograde cholangiopancreatography-related duodenal perforation. Clin Endosc 2014;47:341-345.

7 Howard TJ, et al: Classification and management of perforations complicating endoscopic sphincterotomy. Surgery 1999;126:658-663; discussion 664-665.

-8 Stapfer M, et al: Management of duodenal perforation after endoscopic retrograde cholangiopancreatography and sphincterotomy. Ann Surg 2000;232:191-198.

-9 Williams EJ, et al: Risk factors for complication following ERCP; results of a large-scale, prospective multicenter study. Endoscopy 2007;39:793-801.

10 Cochetti G, et al: Pneumoscrotum: report of two different cases and review of the literature. Ther Clin Risk Manag 2015;11:581-587.

-11 Firman R, et al: Pneumoscrotum. Ann Emerg Med 1993;22:1353-1356.

12 Klimach OE, Defriend DJ, Foster DN: Pneumoscrotum following endoscopic sphincterotomy. Surg Endosc 1990;4:230-231.

13 Silak J, et al: Pneumoscrotum: uncommon sign in duodenal perforation (a case review) (in Czech). Rozhl Chir 2011;90:237-239.

14 Kobborg M, et al: Unusual duodenal perforation following endoscopic retrograde cholangiopancreatography. Gastroenterol Insights 2011;3:e1.

-15 Boumans D, van Zanten RA, Schot BW: A man with painless scrotal swelling. Scrotal emphysema (pneumoscrotum). Neth J Med 2012;70:194, 198.

16 Milone M, et al: Pneumoscrotum after ERCP-related duodenal perforation. Endoscopy 2016;48(S 01): E295. 


\section{Case Reports in Gastroenterology

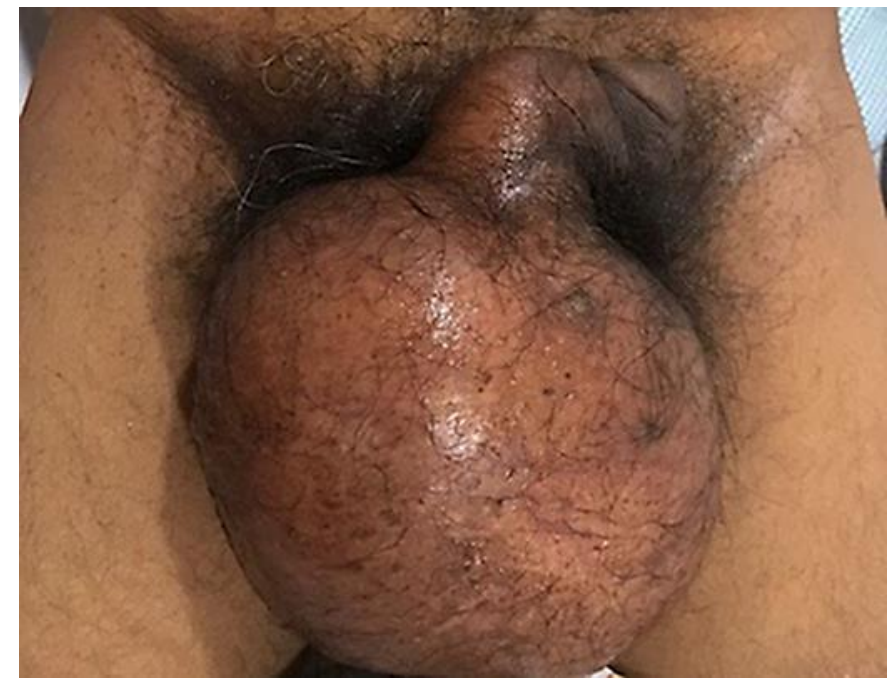

Fig. 1. Clinical photograph showing diffuse scrotal swelling.

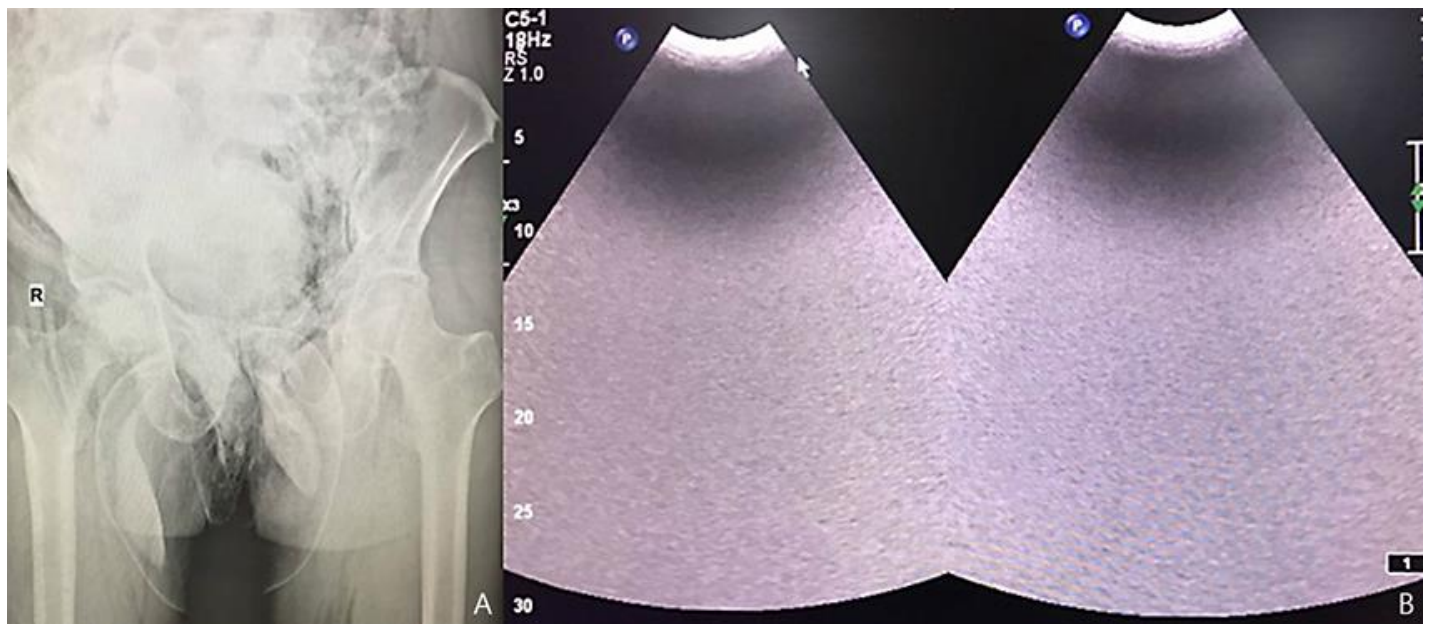

Fig. 2. A Plain radiograph of the pelvis showing an enlarged scrotal shadow with presence of air in it. B Sagittal sonographic image of the scrotum showing a reflection of the ultrasound beam suggesting air inside the scrotum. 


\section{Case Reports in Gastroenterology

\begin{tabular}{l|l}
\hline Case Rep Gastroenterol 2018:12:1-6 \\
\hline DOI: 10.1159/000485557 & $\begin{array}{l}\text { @ 2018 The Author(s). Published by S. Karger AG, Basel } \\
\text { www.karger.com/crg }\end{array}$ \\
\hline
\end{tabular} \\ Khan et al.: ERCP-Related Duodenal Perforation Presenting as Pneumoscrotum}

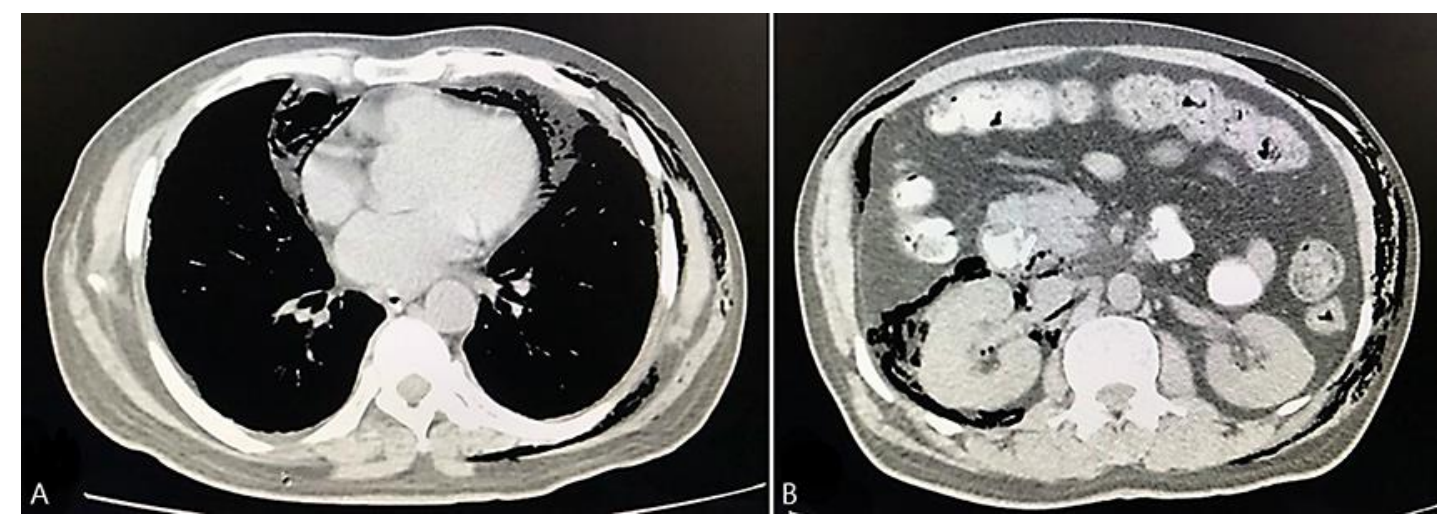

Fig. 3. A Axial CT image of the chest showing pneumomediastinum along with subcutaneous emphysema involving the chest wall on the left side. B Axial CT of the abdomen showing pneumoretroperitoneum surrounding the right kidney along with subcutaneous emphysema.
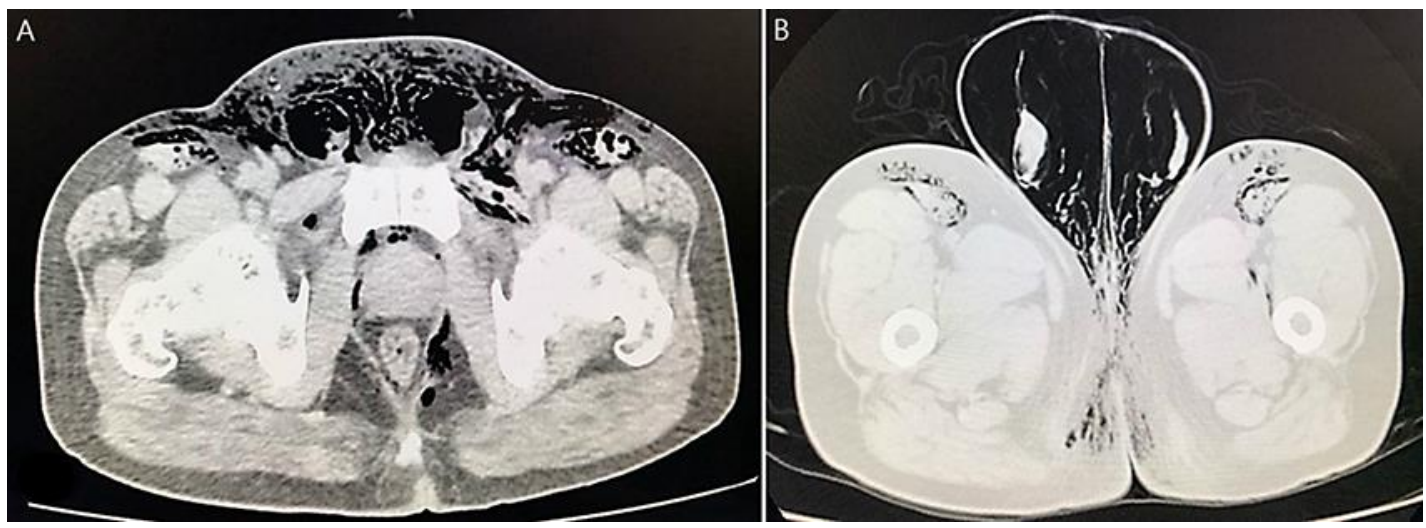

Fig. 4. A, B Axial CT images at the level of the pelvis showing enlargement of the scrotal sac with presence of air inside it consistent with pneumoscrotum. Extensive subcutaneous emphysema involving the perineum and the penile region can be visualized. 